\title{
Mechanical properties and microstructure of large IN713LC nickel superalloy castings
}

\author{
Jiří Zýka ${ }^{1, a}$, Jaroslav Málek ${ }^{2}$, and Karel Hrbáček ${ }^{3}$ \\ ${ }^{1}$ UJP PRAHA a.s., Nad Kamínkou 1345, 156100 Praha 5 - Zbraslav, Czech Republic \\ ${ }^{2}$ Czech Technical University in Prague, Faculty of Mechanical Engineering, Department of Materials Engineering, \\ Karlovo náměstí 13, 12000 Praha 2, Czech Republic \\ ${ }^{3}$ První brněnská strojírna Velká Bíteš a.s., Precision Casting Division, Vlkovská 245, 59512 Velká Bíteš, Czech Republic
}

\begin{abstract}
When approving large castings for use, mechanical values are measured by room temperature tensile test on test bodies made from the centres of the castings. These test bodies often exhibit lower values than required, in particular ultimate tensile strength and elongation. The presence of fragile niobium carbides in the structure of the alloy was identified as the main cause of this situation, which originated as a result of the slow speed cooling. Because of large grain size compared to gauge length diameter, crystal orientation of individual grains also plays an important role. Interdendritic carbides are oriented parallel with dendrites thus parallel with $<100>$ directions in Ni superalloy crystal lattice. Grain oriented with $<100>$ axis parallel to tensile direction has platelet carbides oriented perpendicular to the tensile axis. In that position carbides crack easily at low grain deformation. Longitudinal metallographic cuts of selected tested specimen gauge lengths were prepared and grain orientation of individual grains was investigated by EBSD, Specimens, where grain oriented with $<100>$ axis parallel to tensile direction were found, performed poor elongation values $3 \%$, compared to $7 \%$ where no such oriented grains were found.
\end{abstract}

\section{Introduction}

IN713LC nickel superalloy is currently used widely, for example, for manufacturing of turbine wheels in turbochargers. Recently, customers demand production of increasingly larger impeller parts than before. This requirement has resulted in a greater castings weight implying different solidification and cooling conditions during casting process. Therefore modified castings microstructure arises, e.g. large grains, larger gamma prime phase particles and long interdendritic carbides.

When approving large castings for use, mechanical values are measured by room temperature tensile test on test bodies made from the centres of the castings. These test pieces often exhibit lower values than required, in particular ultimate tensile strength and elongation. Therefore an investigation was performed to find the cause of such poor mechanical properties.

\section{Experimental}

The chemical composition of the IN713LC alloy used is given in Table 1.

Turbocharger rotor castings, weight $7.5 \mathrm{~kg}$, were cast by vacuum investment casting process in PBS Velká Bíteš foundry. According to the tensile test on test specimens with $6 \mathrm{~mm}$ diameter were made from material cut out

\footnotetext{
${ }^{a}$ Corresponding author: zyka@ujp.cz
}

Table 1. Chemical composition (in wt. \%) of the IN713LC alloy.

\begin{tabular}{|l|l|l|}
\hline & Min. & Max. \\
\hline $\mathrm{Cr}$ & 11 & 13 \\
\hline $\mathrm{Ti}$ & 0.4 & 1 \\
\hline $\mathrm{Al}$ & 5.5 & 6.5 \\
\hline $\mathrm{Mo}$ & 3.8 & 5.2 \\
\hline $\mathrm{Ta}$ & 0.75 & 1.1 \\
\hline $\mathrm{Nb}$ & 0.75 & 1.1 \\
\hline $\mathrm{Fe}$ & 0 & 0.5 \\
\hline $\mathrm{Si}$ & 0 & 0.5 \\
\hline $\mathrm{Mn}$ & 0 & 0.25 \\
\hline $\mathrm{C}$ & 0.03 & 0.07 \\
\hline $\mathrm{Cu}$ & 0 & 0.5 \\
\hline $\mathrm{Zr}$ & 0.05 & 0.1 \\
\hline $\mathrm{B}$ & 0.005 & 0.015 \\
\hline $\mathrm{Ni}$ & Bal. & Bal. \\
\hline
\end{tabular}

from centres of the castings. Experimental work consisted of tensile test at room temperature and deformation rate $2.8 \cdot 10^{-4}$.

Consequent metallographic (light metallography LM) analysis was performed on longitudinal metallographic cuts. Voids and carbides fraction were measured in non-etched state, for grain size measurement $\mathrm{HCl}+\mathrm{H}_{2} \mathrm{O}_{2}$ etch was used. Electrolytic etching in oxalic acid solution was used for $\gamma^{\prime}$ particles characterisation in scanning

This is an Open Access article distributed under the terms of the Creative Commons Attribution License 4.0, which permits unrestricted use, distribution, and reproduction in any medium, provided the original work is properly cited. 
Table 2. Mechanical and structural properties of selected tensile specimen.

\begin{tabular}{|l|l|l|l|}
\hline & C6543-1 & C6544-3 & C6540-2 \\
\hline Rp0.2 [MPa] & 672.0 & 643.7 & 654.3 \\
\hline Rm [MPa] & 693.2 & 686.1 & 679.1 \\
\hline A [\%] & 6.0 & 8.6 & 3.3 \\
\hline Average grain size [mm] & 5.14 & 7.33 & 5.81 \\
\hline Void fraction on fracture [\%] & 0.02 & 0.00 & 0.94 \\
\hline Void fraction on section [\%] & 0.14 & 0.14 & 0.34 \\
\hline Carbides fraction on section [\%] & 0.60 & 0.70 & 0.64 \\
\hline
\end{tabular}

electron microscope. Grain size, gamma prime phase size, amount of casting defects and carbides were determined.

Fracture surfaces were investigated by optical camera and subsequent fractographic analysis was performed by means of scanning electron microscopy.

Grain orientation analysis by means of EBSD was performed on same metallographic cuts etched by oxalic acid.

\section{Results}

\subsection{Mechanical properties}

Set of 9 tensile specimens was tested. Seven of them exhibited low elongation values, under $3.5 \%$. Mechanical properties of these low elongation specimen are represented by specimen C6540-2 in Table 2. The table contains also results of the only two specimens with satisfying elongation values.

\subsection{Microstructure analysis}

The main microstructure feature is the average grain size over $5 \mathrm{~mm}$, which is close to the diameter of the tested specimens. Some grains are larger than the specimen's diameter, therefore proper estimation of their size was not possible. Hence grain size values given in Table 2 are rather qualitative. Fig. 1 .

Macrostructure of studied specimen is exhibited in

$\gamma^{\prime}$ phase particles characteristics of investigated specimens are given in Table 3. Main feature is large average particle size Dv, slightly over $1 \mu \mathrm{m}$, which is result of the slow cooling condition. Volume fraction $\mathrm{Vv}$ is high, between 67 and 69\%. Average volume particle number Nv and average interparticle distance Dv were calculated too. No important differences were found between the three specimens.

\subsection{Fracture mechanism analysis}

Failed specimens exhibit different amount of reduction of area, see Figs. 1 and 2, which seems anisotropic in case of specimen with high elongation.

Fracture surface of specimen with low elongation is flat, with shiny areas. At a microscale level the same fracture surface is covered by many cleavaged carbide particles, see Fig. 3. Some casting defects are present too as shown in Fig. 3b.

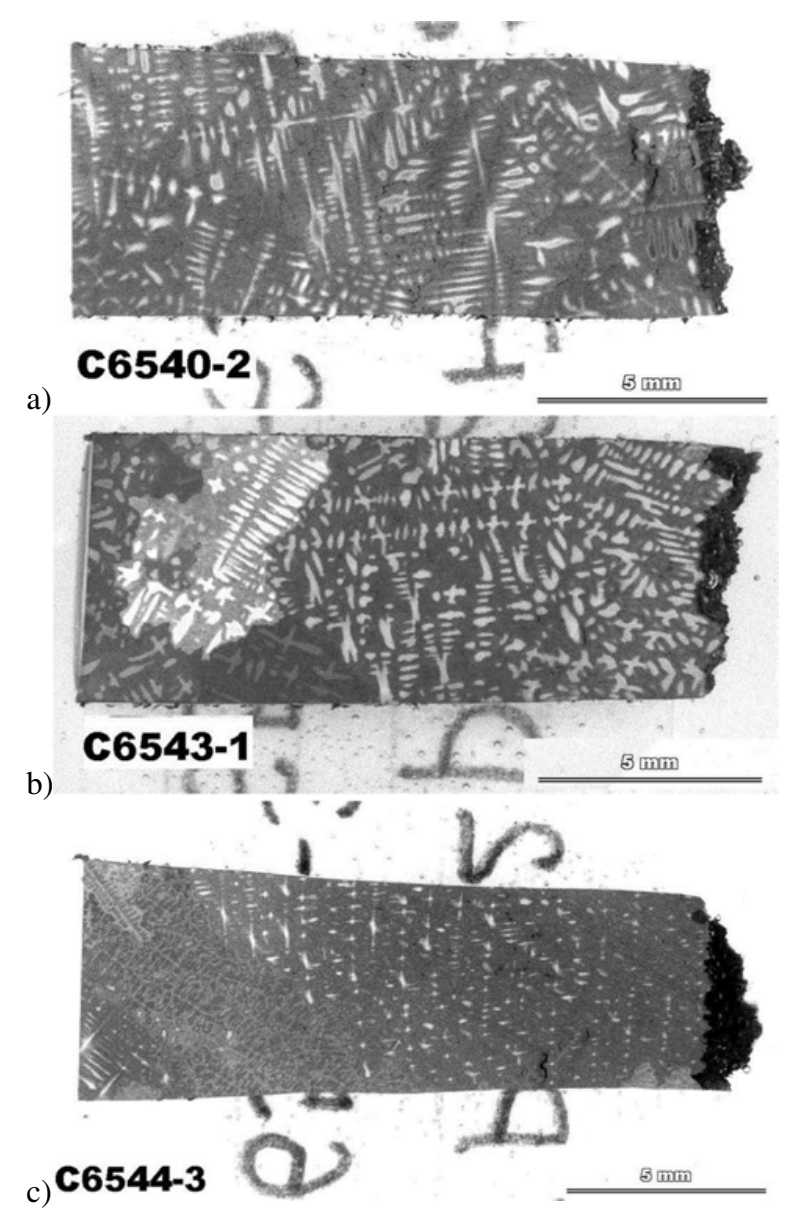

Figure 1. Examples of macrostructure of studied specimen (LM).

Table 3. Mechanical and structural properties of selected tensile specimen.

\begin{tabular}{|c|c|c|c|c|c|c|}
\hline & \multicolumn{3}{|c|}{ C6543-1 } & \multicolumn{2}{l|}{ C6544-3 } & \multicolumn{2}{c|}{ C6540-2 } \\
\hline & Mean & St. Dev. & Mean & St. Dev. & Mean & St. Dev. \\
\hline $\mathbf{D v}[\boldsymbol{\mu \mathbf { m }}]$ & 1.13 & 0.12 & 1.03 & 0.12 & 1.07 & 0.08 \\
\hline $\begin{array}{c}\mathbf{N v} \\
{\left[\boldsymbol{\mu \mathbf { m } ^ { - 3 }}\right]}\end{array}$ & 1.13 & 0.39 & 1.3 & 0.4 & 1.13 & 0.19 \\
\hline $\mathbf{L v}[\boldsymbol{\mu} \mathbf{m}]$ & 0.46 & 0.06 & 0.45 & 0.06 & 0.46 & 0.04 \\
\hline $\mathbf{V v}[\%]$ & 67.55 & 1.54 & 68.49 & 2.95 & 66.67 & 2.1 \\
\hline
\end{tabular}

Fracture surfaces of specimen with high elongation exhibit more microroughness and more signs of ductile deformation, see Fig. 4. Cracked carbides are also present.

Non-etched longitudinal cuts of failed specimens are depicted in Fig. 5. where tensile direction is oriented horizontally. Main feature are cracked interdendritic carbides, but with different orientation to tensile direction. In specimens with low elongation, carbide platelets are oriented perpendicularly to the tensile stress, thus promoting their longitudinal cracking and interconnecting of such cracks. In specimen with high tensile elongation, the angle between carbide platelets and tensile direction is smaller. Thus carbide particle cracks in several nonconnected cracks as shown in Fig. 6. 
a) $\mathbf{C 6 5 4 0 - 2}$

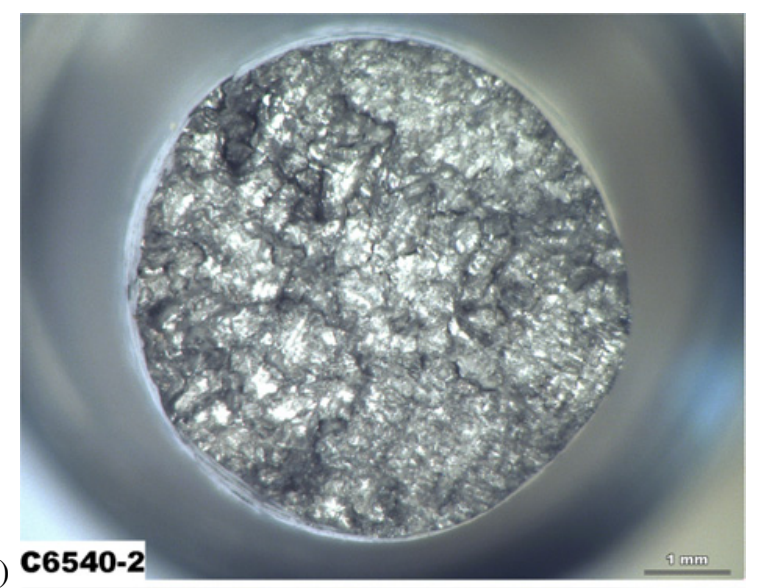

b)
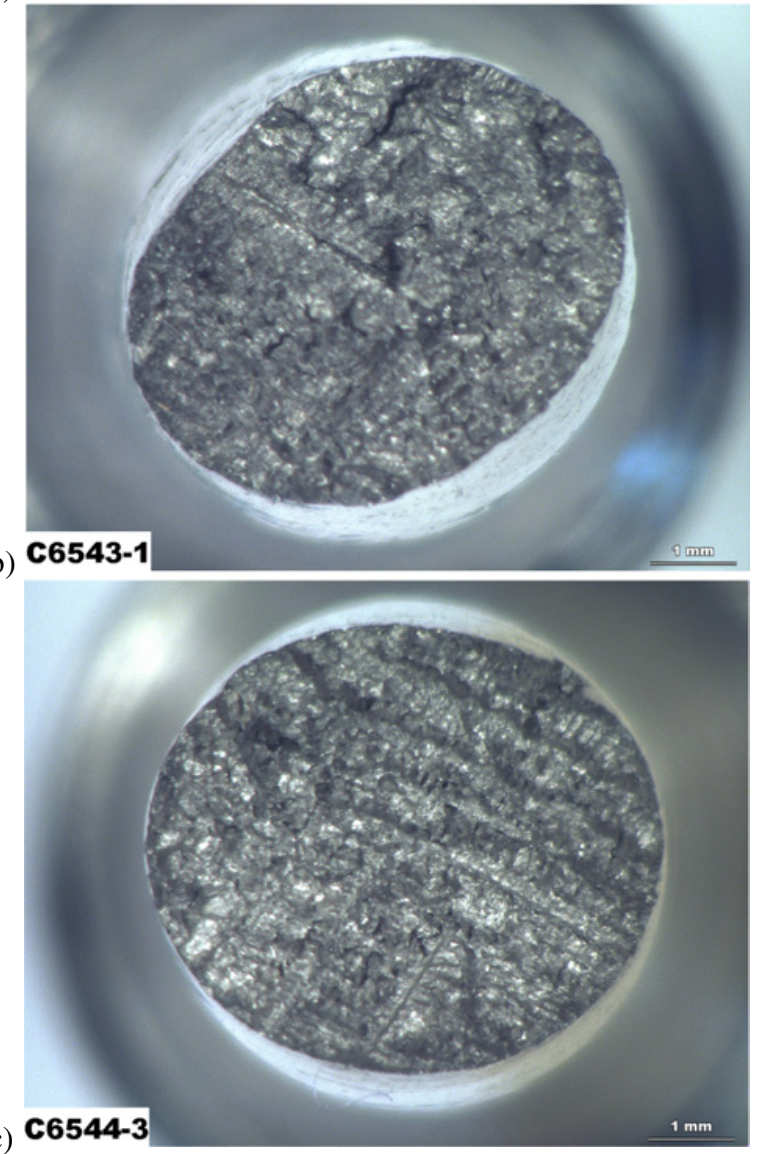

Figure 2. Fracture surfaces of studied specimen, optical camera.

\subsection{Grain orientation analysis}

Anisotropic deformation of specimens with high elongation shown in Figs. 1 and 2 indicates that orientation of individual anisotripic grains may influence deformation and fracture mechanisms of studied failed tensile specimens. Hence a grain orientation analysis on longitudinal specimens' cuts by means of EBSD was performed.

The whole surface of all of longitudinal cuts was analysed by EBSD. Tilting angle during the EBSD analysis was set to $65^{\circ}$. Step between individual analysed spots was set to $70 \mu \mathrm{m}$, which was found appropriate for large grains

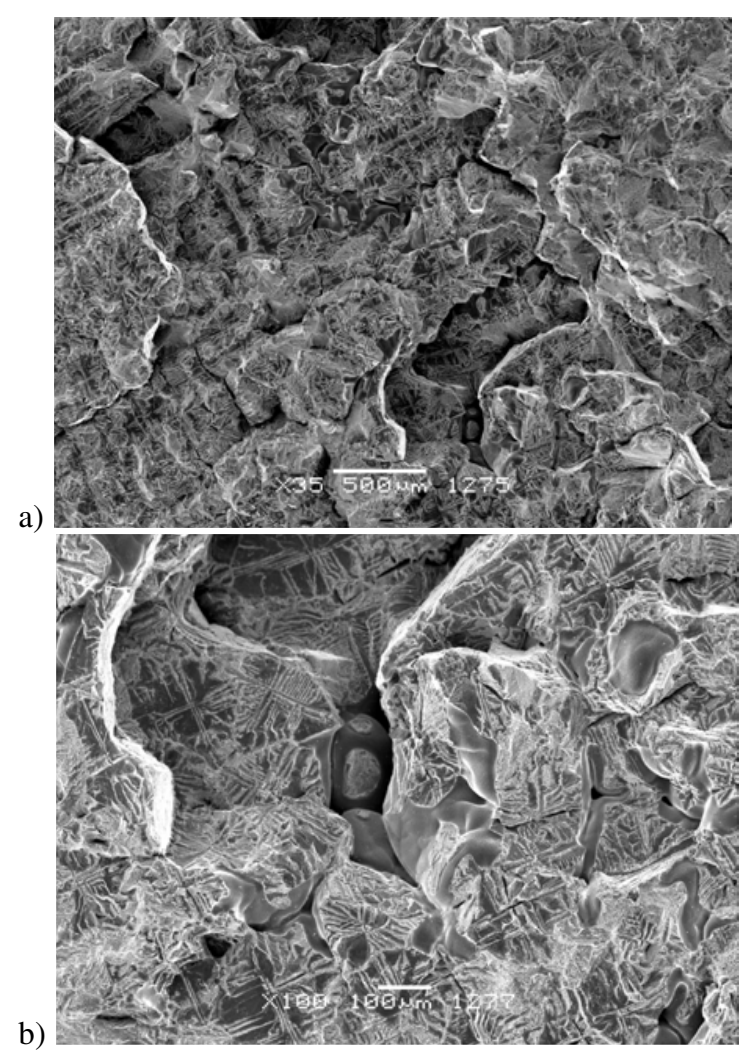

Figure 3. SEM micrographs of fracture surface of specimen with low elongation.

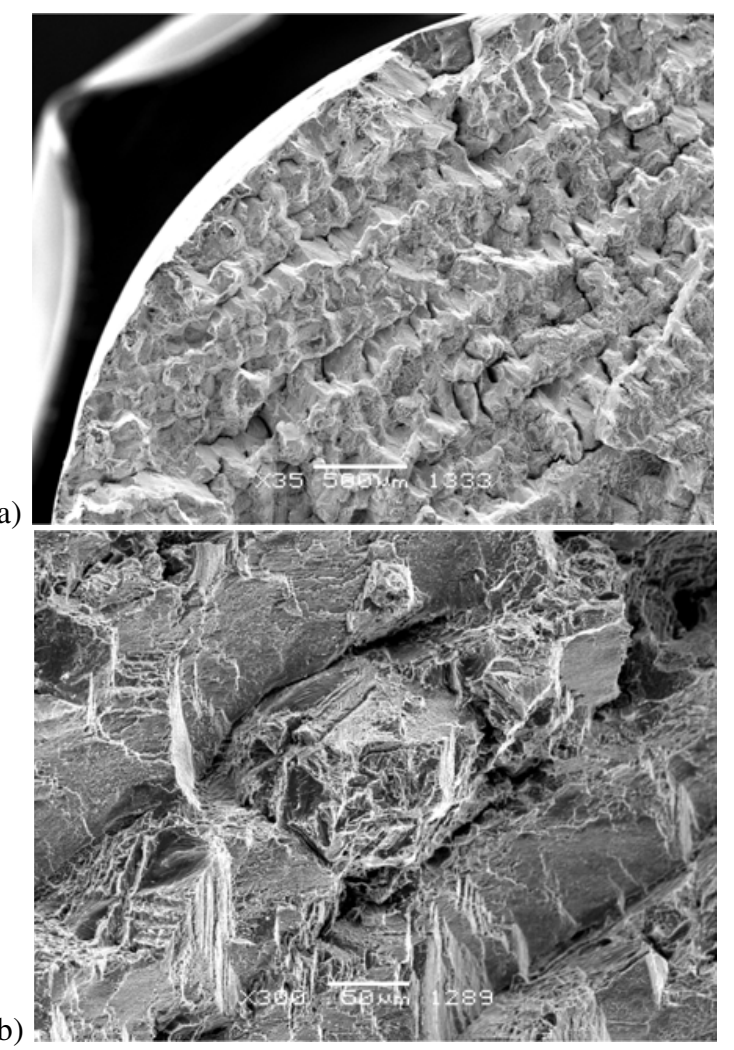

Figure 4. SEM micrographs of fracture surface of specimen with low elongation. 
a)

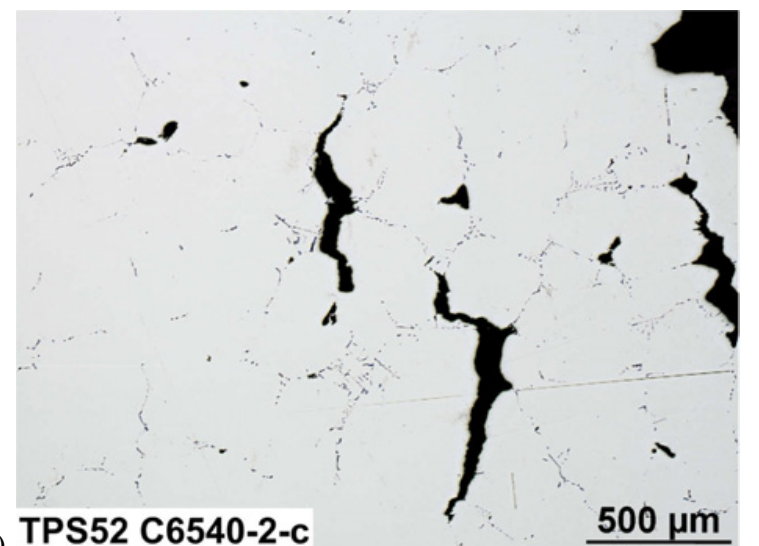

TPS52 C6540-2-c

b)

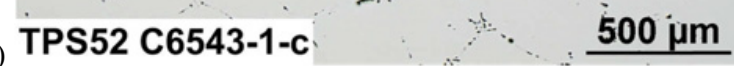

c) C6544-3-L1

Figure 5. LM micrographs of broken interdendritic carbides in specimen with low elongation a) and high elongation b), c).

investigation. Data were collected without tilt correction to reduce analysis time.

Grain orientation maps are depicted in Fig. 7 with tilt correction. Main difference is area fraction of grains with $<100>$ orientation. Specimens with high elongation contain a few very small grains with such orientation.

Inverse pole figures (IPF) were calculated showing orientation of specimens' longitudinal axis, hence tensile axis, in Ni superalloys FCC crystal lattice. Measured data, over 20000 measured points, from whole each test specimen were integrated in depicted inverse pole figures with contouring in Fig. 8.

We can see important differences in IPF. Longitudinal cuts of specimen C6540-2 contain dominantly grains with orientation $<100>$, and $<110>$, and $<112>$.

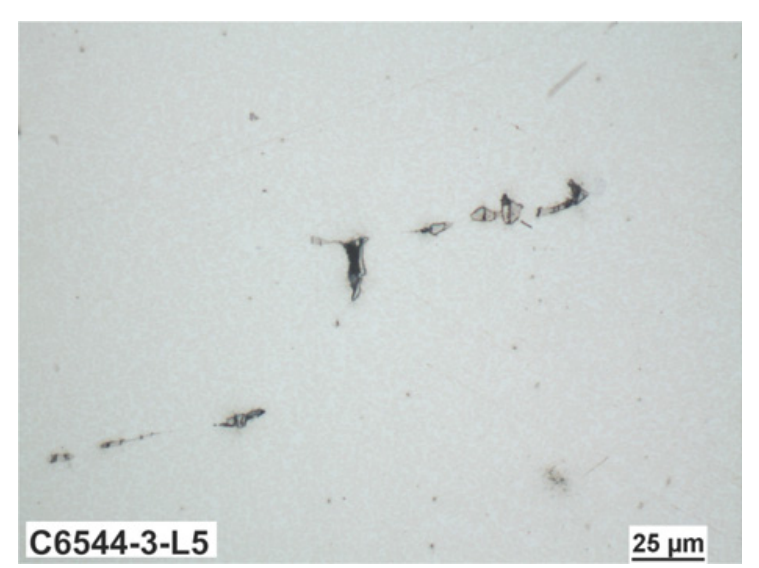

Figure 6. Detail of broken interdendritic carbides in specimen with high elongation.
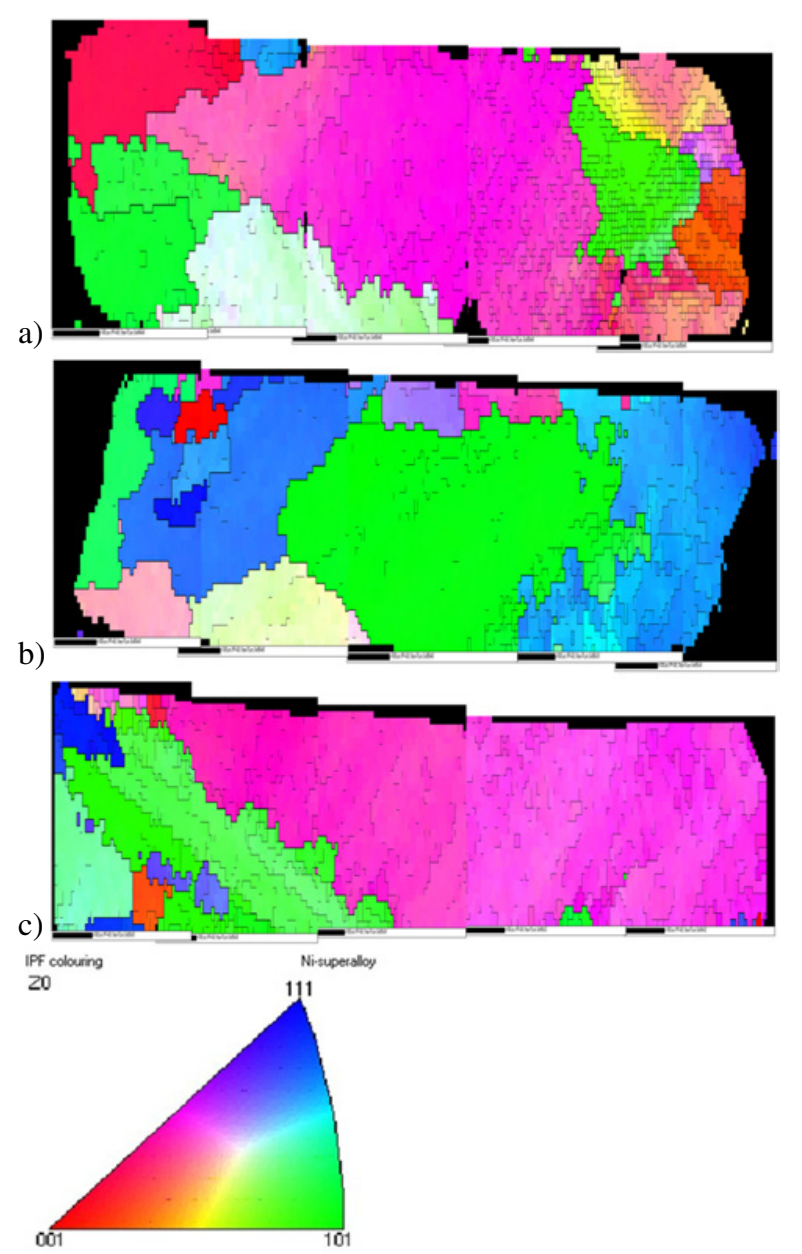

Figure 7. Grain orientation maps of broken specimen with low elongation a) and high elongation b), c).

Majority of grains found on cuts of specimen C65431 shows orientation $\langle 110\rangle,<111\rangle$, and $<112>$. Very low number with low area of 100 oriented grains was found.

Longitudinal cuts of specimen C6544-3 contain mostly grains with orientation close to $<111>$, and $<112>$ and low amount of $<100>$ and $<110>$ oriented grains. 


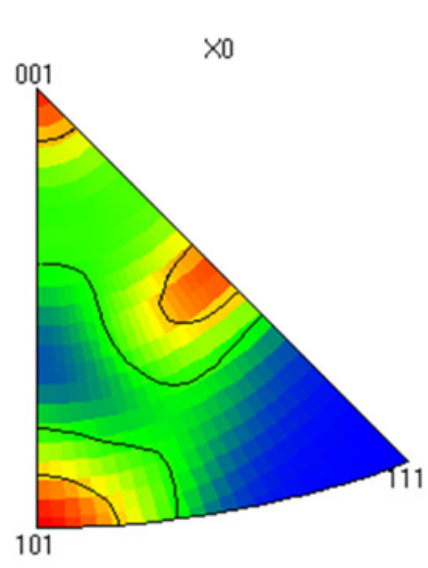

a)

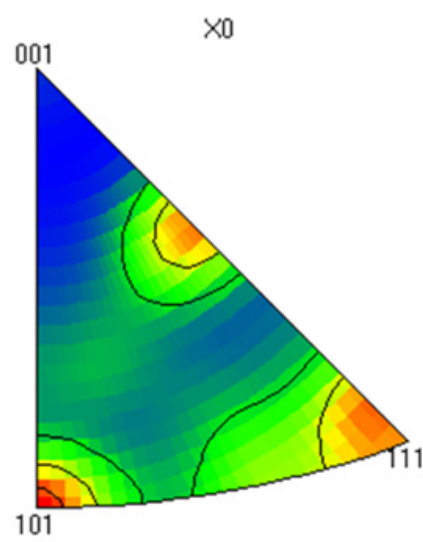

b)

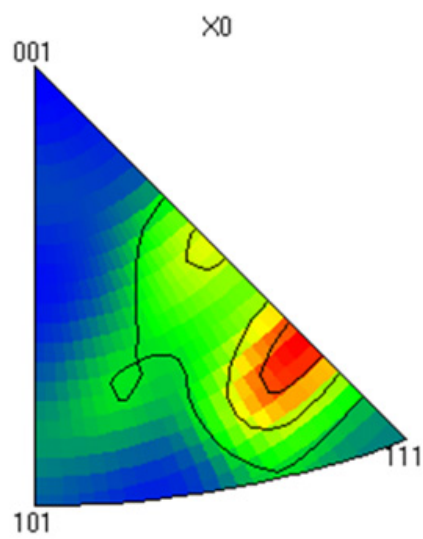

c)

Figure 8. Inverse pole figures showing orientation of specimens' longitudinal axis, hence tensile axis, in Ni superalloys FCC crystal lattice low elongation a) and high elongation b), c).

Since specimen C6540-2 exhibited the lowest elongation and specimen C6544-3 the highest, it seems, that occurrence of grains with $<100>$ orientation is least favourable for plastic deformation. On the contrary $<111>$ orientation seems the most favourable for good elongation in investigated nickel superalloy IN713LC with large amount of interdendritic carbides.

\section{Discussion}

The connection between measured differences in tensile properties and microstructure can be discussed with the

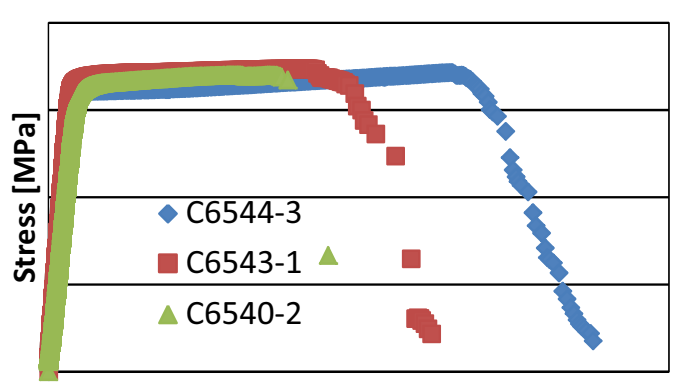

Deformation [\%]

Figure 9. Stress strain curves of investigated specimen.

help of stress strain curves of investigated specimens depicted in Fig. 9.

There is linear stress strain correlation during homogenous plastic deformation. No differences between specimens were found.

Localised plastic deformation, necking, appears first in specimen with low elongation. But necking is very short without important plastic deformation (see Figs. 1a and 2a) the specimen breaks. Main fracture mechanism is longitudinal cracking of interdendritic carbides oriented perpendicularly to tensile axis, see Fig. 3. There is a large grain with $<100>$ orientation under the fracture surface (see Fig. 7a) with secondary cracks of this type, see Figs. 1a, 5a.

Specimen with elongation value $6 \%$ begins to neck roughly at the same strain as the first specimen. But necking is longer resulting in an important plastic deformation of material close to fracture, see Figs. 1b and 2b. Fracture mechanism is more ductile, see Fig. 4. There is a large grain with $<111>$ orientation under the fracture surface, see Fig. 7b. Very low area fraction of 100 oriented grains was observed, see Fig. 8b.

Specimen with elongation value $9 \%$ begins to neck at a larger strain, roughly at $6 \%$. Necking is also long resulting in another important plastic deformation of material close to fracture. Fracture mechanism is more ductile, see Fig. 4. There is a large grain with $<112>$ orientation under the fracture surface, with small not connected cracks of interdendritic carbides, see Fig. 5c and Fig. 6. Very low area fraction of 100 oriented grains was found, see Fig. 8c.

Carbide platelets in grains with $<100>$ orientation are oriented perpendicularly to tensile stress, thus promoting their longitudinal cracking and interconnecting of such cracks. In specimen with no grains with $<100>$ orientation, the angle between carbide platelets and tensile direction is smaller. Thus carbide particle breaks in several non-connected cracks.

Since there is a correlation of elongation (A) and rupture strength $(\mathrm{Rm})$ during homogenous plastic deformation, $\mathrm{Rm}$ and $\mathrm{A}$ values are closely connected. When the alloy tends to deform easily, values of $\mathrm{Rm}$ are higher, when fragile obstacle for dislocation movement occurs, Rm and A values are rather lower.

Similar fracture behaviour of cast polycrystalline nickel superalloys was reported before [1,2] and [3]. It was concluded that presence of carbide particles is cause of low elongation values. Influence of coexisting casting voids on elongation was discussed in [3]. Elongation values as 
low as $1.6 \%$ were measured in case of castings with $0.8 \%$ fraction of carbides and with no casting defects found. Thus we can assume that difference found in volume fraction of casting voids in investigated specimens is not the main cause of their different deformation and fracture behaviour.

\section{Conclusion}

Heavy IN713LC nickel superalloy castings were investigated. It was shown that room temperature tensile properties are directly influenced by castings microstructure and thus solidifying and cooling conditions. Most important microstructure feature is the presence of interdendritic carbides. The negative effect of carbides on plastic properties of cast superalloys is correlated to their orientation to tensile stresses applied. Grain oriented with
$<100>$ axis parallel to tensile direction has platelet carbides oriented perpendicular to the tensile axis, thus promoting their longitudinal cracking and interconnecting of such cracks.

This research was sponsored by the Czech Ministry of Industry and Trade, programme TIP, project FR-TI3/055.

\section{References}

[1] M. Donachie, S. Donachie, Superalloys: A Technical Guide - 2nd edition, ASM International, 2002, pp. 37

[2] D. Bettge, W. Österle, J. Ziebs, Z. Metallkd. 86 (1995) 3

[3] J. Zýka, I. Andršová, B. Podhorná, B., K. Hrbáček, Proceedings of Metal 2013 